\title{
1 Selection of hydrological signatures for large-sample hydrology
}

2

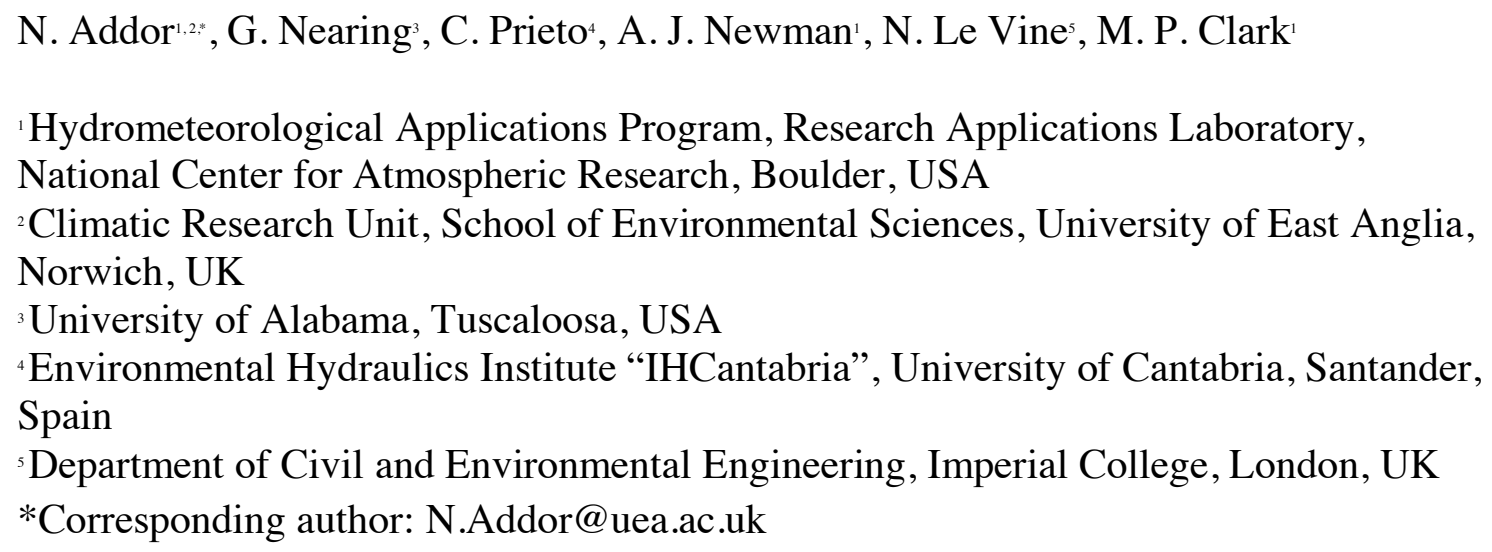

\section{Key points}

There is a need for a framework to support the selection of hydrological signatures for experimental and modeling studies.

We rank signatures based on their predictability in space, different predictions methods yielding very similar results.

We identify difficulties emerging when moving down the ranking, which can compromise the utility and reliability of the signatures.

\begin{abstract}
Hydrological signatures are now used for a wide range of purposes, including catchment classification, process exploration and hydrological model calibration. The recent boost in the popularity and number of signatures has however not been accompanied by the development of clear guidance on signature selection, meaning that signature selection is often arbitrary. Here we use three complementary approaches to compare and rank 15 commonly-used signatures, which we evaluate in 671 US catchments from the CAMELS data set (Catchment Attributes and MEteorology for Large-sample Studies). Firstly, we employ machine learning (random forests) to explore how attributes characterizing the climatic conditions, topography, land cover, soil and geology influence (or not) the signatures. Secondly, we use a conceptual hydrological model (Sacramento) to critically assess which signatures are well captured by the simulations. Thirdly, we take advantage of the large sample of CAMELS catchments to characterize the spatial smoothness (using Moran's $I$ ) of the signature field. These three approaches lead to remarkably similar rankings of the signatures. We show that signatures with the noisiest spatial pattern tend to be poorly captured by hydrological simulations, that their relationship to catchments attributes are elusive (in particular they are not correlated to climatic indices like aridity) and that they are particularly sensitive to discharge uncertainties. We question the utility and reliability of those signatures in experimental and modeling hydrological studies, and
\end{abstract}


we underscore the general importance of accounting for uncertainties in hydrological signatures.

\section{Introduction}

Hydrological signatures (indices characterizing hydrologic behavior) are now commonly used to understand space-time variability in hydrological processes (Troch et al., 2009; Sawicz et al., 2011) and to diagnose weaknesses in hydrological models (Gupta et al., 2008; Euser et al., 2013; Vrugt and Sadegh, 2013). Signatures can be computed using a wide range of data sources (such as soil moisture or snow data), but in practice they are most often computed using discharge time series (e.g., Yilmaz et al., 2008). Hydrological signatures are particularly useful to characterize and compare the dynamics of large samples of catchments, for which only limited observations are available (discharge is measured, but evapotranspiration, snow water equivalent, tracer concentrations or water table level are usually not measured). In a sense, hydrological signatures are an indirect way to explore hydrological processes, when those processes cannot be isolated because of the lack of measured data. This enables in particular catchment classification (Sawicz et al., 2011) and provides insights into hydrological behavior in places where little to no data are available (Kuentz et al., 2017).

A profusion of hydrological signatures already exists, and more are being developed. The diversity of hydrologic signatures enables characterizing a wide variety of hydrological features, but at the same time, makes selecting appropriate signatures challenging (McMillan et al., 2017). There are some general selection criteria; for instance, it is desirable that i) signatures can be related to hydrological processes to enable a better understanding of particular aspects of catchment behavior, ii) they are sensitive to processes occurring over different periods (from the sub-daily to the decadal time scale), and iii) they are not redundant. Yet, signature selection is essentially dealt with on a caseby-case basis, different studies invariably use different signatures, and the same signatures may be computed in different ways (e.g., the baseflow index). While it is normal that each study selects signatures to meet its specific needs, there is a need to develop general guidance on the selection of hydrologic signatures.

Our key contribution is a general framework to understand the utility of different signatures. Previous work has focused on specific aspects of signatures like their regionalization (Beck et al., 2015; Almeida et al., 2016), their sensitivity to discharge measurement errors (Westerberg et al., 2016) or their use for model calibration (Euser et al., 2013; Hrachowitz et al., 2014) or model selection (Clark et al., 2011; McMillan et al., 2011). All these aspects are important for signature selection, but they are difficult to account for simultaneously. Although the studies just mentioned are related, they have been essentially conducted independently. This study aims to synthesize insights gained from different perspectives on hydrological signatures. We developed a framework to compare and organize 15 commonly-used signatures, which we evaluated over 671 catchments in the contiguous United States (CONUS). We explore i) how well signatures can be predicted from catchments attributes (using random forests), ii) how well they can

88 be simulated (using a conceptual hydrological model) and iii) how smoothly they vary in 
space.

Our approach is motivated by the general idea that "the ability to accurately predict behavior is a severe test of the adequacy of knowledge in any subject" put forward by Crawford and Linsley (1966). We argue that the failure to predict a signature is symptomatic of limitations of our understanding of what it represents, and/or of limitations of data we use to compute or predict it. Here we explore and reveal limitations of hydrological signatures, and argue that this can help to guide signature selection. Our approach is driven by three main research questions:

1. How well can signatures be predicted using landscape characteristics? With this question, we try to better understand how the interplay of landscape attribute shape hydrological behavior. We used a statistical model (random forests) to relate catchments attributes to hydrological signatures.

2. How well can signatures be simulated by a conceptual hydrological model calibrated using an aggregated measure of performance? We used signatures to critically assess the realism of simulations from a model calibrated using RMSE. Our aim is to examine shortcomings of simulations resulting from this kind of traditional (and still prevalent) parameter estimation technique.

3. How smoothly do signatures vary in space? We explored the spatial patterns of signatures drawn when plotting their value for 671 catchments. We used those patterns to reflect on whether signature variations in space truly reflect differences in hydrological processes, or rather, data and method uncertainties.

The analysis in this paper enables us to compare and rank signatures, and to provide general guidance for their selection and use. The remainder of this paper is organized as follows: The data and methods are presented in Section 2; the ranking of signatures is presented in Section 3; the implications for signature selection are discussed in Section 4; conclusions and future research needs are presented in Section 5.

\section{Data and methods}

\subsection{The CAMELS data set}

All the data used in this study come from the CAMELS data set (Catchment Attributes and MEteorology for Large-sample Studies). The CAMELS data set covers 671 catchments in the contiguous US (CONUS) and consists of two types of data: daily time series the atmospheric forcing and discharge (Newman et al., 2014, 2015) and catchment attributes selected to provide a quantitative description of landscape features likely to influence hydrological processes (Addor et al., 2017a, 2017b). The hydrometeorological time series and catchment attributes are described in Sections 2.2 and 2.3, respectively.

\subsection{CAMELS hydrometeorological time series}

The hydrometeorological time series include both daily meteorological forcing and observed discharge time series, as well as daily hydrological simulations. Precipitation and temperature at the catchment scale were retrieved from the Daymet data set 
131 (Thornton et al., 2012). Potential evapotranspiration was estimated based on Priestley and 132 Taylor (1972). The hydrologic simulations were produced using the Sacramento Soil 133 Moisture Accounting model (Burnash et al., 1973) combined with the SNOW-17 snow 134 accumulation and ablation model (Anderson, 1973), with streamflow being routed using 135 a unit-hydrograph model. Hereafter this modeling setup is referred to as SAC. SAC was 136 calibrated using the shuffled complex evolution (SCE, Duan et al., 1992) global 137 optimization routine, minimizing the root mean squared error (RMSE) of the discharge 138 simulations. Simulations started on October 1* 1980 for the 598 basins (out of 671) for which discharge measurements started on or before that date. For the other basins, simulations started on the first October $1^{\text {st }}$ after the start of the discharge records. SAC was calibrated over the first 15 years of the simulation for each catchment, meaning that different periods were used for different catchments. For each catchment, SCE was started from 10 different random seeds, which led to 10 optimized parameter sets. Further details on the hydrometeorological time series are provided in Newman et al. (2015).

\subsection{CAMELS catchment attributes}

146 The landscape of each catchment was described using a wide range of attributes, which can be divided into five classes:

1. Topographic characteristics: features such as catchment area and mean elevation, extracted from the United States Geologial Survey (USGS) data base.

2. Climatic indices: indices such as aridity and the frequency of high precipitation events, computed using the Daymet (Thornton et al., 2012) daily time series extracted by Newman et al. (2015).

3. Land cover characteristics: attributes such as the maximum leaf area index and the rooting depth, estimated using MODIS imagery.

4. Soil characteristics: variables such as the soil depth and the sand fraction, extracted from the State Soil Geographic Database (STATSGO, Miller and White, 1998) and from Pelletier et al. (2016).

5. Geological characteristics: characteristics such as the dominant geology class and the subsurface permeability, retrieved from Global Lithological Map (GLiM, Hartmann and Moosdorf, 2012) and GLobal HYdrogeology MaPS (GLHYMPS, Gleeson et al., 2014).

The complete list of catchment attributes, as well as details on the methods and data used to compute them, is provided in Table 1. Note that not all of the CAMELS attributes were used. We excluded the following attributes to avoid redundant information and clarify the result of the statistical analysis: the leaf area index difference and green vegetation fraction difference (both are highly correlated with the leaf area index maximum), mean slope (correlated with mean elevation, but more delicate to estimate), soil porosity and conductivity (both are highly correlated with the sand fraction because of their estimation relying on sand fraction) and the second dominant geological class of the GLiM data set (as it is unavailable for 138 catchments, which are entirely covered by a single class).

174 To characterize the hydrological behavior of the catchments, we computed 15 
175 hydrological signatures. Those signatures were selected because they characterize 176 different parts of the hydrograph and they are sensitive to processes occurring over 177 different time scales. They are also commonly employed in the literature, so we used this 178 study as an opportunity to compare them. The signatures we considered are described in 179 Table 2. We computed them using the observed discharge and the mean of the 10 SAC 180 simulations produced for each catchment. We also predicted these signatures based on 181 catchment attributes using random forests (Section 2.4). We evaluated the signatures 182 simulated by SAC and predicted by random forests by computing the fraction of variance $183\left(\mathrm{R}^{2}\right)$ of the observed signatures that they explain. The number of stations used for $\mathrm{R}^{2}$ 184 computation varies slightly from signature to signature, because in some specific 185 situations, for instance when rivers are dry for significant periods, the signatures cannot 186 be computed. The number of catchments for each signature is however always greater 187 than $600 . \mathrm{R}^{2}$ is unitless, which enables the direct comparison of different signatures. All 188 the signatures were computed using daily discharge data scaled by the catchment area. 189 Further details on the data and methods used to compute the catchment attributes and 190 hydrological signatures are provided in Addor et al. (2017b).

\section{$191 \quad 2.4 \quad$ Random forests to predict hydrological signatures using catchment attributes}

192 We used random forests to predict hydrological signatures using catchment attributes. 193 Random forests are a machine-learning algorithm relying on a large number of regression 194 trees to produce an ensemble of predictions. They have been successfully used in a 195 various fields of geosciences, for instance to predict hydrological signatures (Snelder et 196 al., 2009) and soil characteristics (Chaney et al., 2016; Hengl et al., 2017). We provide a brief introduction to random forests in Appendix 1. For more detailed information, we refer the reader to Breiman (2001). We developed random forests in R (R Core Team, 2017) using the package randomForest (Liaw and Wiener, 2002). For an introduction to random forests using $\mathrm{R}$, we recommend James et al. (2013).

We selected random forests for the data mining of the CAMELS data set for the following reasons:

1. Random forests allow for multiple predictors and non-linear relationships: It is common to use a single characteristic (typically aridity or the baseflow index) to summarize hydrological behavior and differentiate between catchments. Yet, catchment behavior is never determined by a single attribute, but instead reflects the interplay of numerous attributes. Beck et al. (2015) explored streamflow characteristics for thousands of catchments and concluded that "the individual relationships between catchment attributes and Q characteristics were generally weak, suggesting the need for models incorporating multiple predictors to estimate $\mathrm{Q}$ characteristics". Random forests are well-adapted for this task because they allow for multiple predictors, and since they are constructed using a series of thresholds, they can outperform classical multiple linear regressions when the response is not linear. 
Manuscript submitted to Water Resources Research on 17/01/2018.

2. Random forests are not limited by our understanding of catchment behavior: Random forests are a flexible statistical model, which is not constrained by any physical principles or assumptions on hydrological processes. We see it as an advantage, as data exploration using random forest can potentially reveal relationships, which are not commonly acknowledged, although they can be explained a posteriori from a physical perspective.

3. Reduced risk of data overfitting: Random forests are an ensemble of regression trees, which gives them more robustness than individual regression trees. Randomness is introduced when they are constructed so that their predictions are not overly influenced by specific catchments or predictors (Appendix 1). The random forest predictions were evaluated using a ten-fold cross-validation: a random forest was trained using $90 \%$ of the basins and its predictions were evaluated using the remaining basins, this procedure was then repeated nine additional times in order to cover all the basins. The results showed hereafter are for the validation phase, not for the training phase.

4. Transparency and interpretability: When producing multi-variable predictions, it is important to be able to assess which predictors have the greatest influence on the response variables. Interpreting the coefficients of a multiple regression is an option (e.g., Almeida et al., 2012), but this does not deliver as clear of a picture, because there can be differences between the predictors of several orders of magnitude. In contrast, the interpretation of the influence of each predictor in the random forest using IncMSE is straight-forward (IncMSE is the relative increase in the MSE of the prediction when the values of the predictor of interest are shuffled, see Appendix 1).

5. Good performance in prediction mode and reliable uncertainty estimates: Random forests and similar machine-learning techniques (such as neural network, e.g. Beck et al., 2015) can deliver accurate predictions for little computation effort (growing each forest takes a few seconds). Further, each random forest relies on an ensemble of trees, that can be used to estimate the uncertainty of the prediction (those uncertainty estimates can be very reliable, see Figure A1d).

We argue that these advantages justify the use of random forests in our study. It is however fair to acknowledge that random forests also have drawbacks. Critically, they are highly parameterized, as each regression tree uses on the order of 10 thresholds. In this study, we used 500 trees to predict each of the 15 hydrological signatures, which leads to about 70,000 parameters (thresholds on predictors). This number of parameter is impractical to analyze on an individual basis, but the relative influence of the predictors on each signature can be quantified using the IncMSE.

\section{Results}

The presentation of the results is organized as follows. We first present spatial maps for a subset of commonly used signatures (mean discharge, slope of the flow duration curve, and the baseflow index), and then we present statistics for the full set of 15 signatures. 
Manuscript submitted to Water Resources Research on 17/01/2018.

262 Finally, we show the influence of individual catchment attributes on random forest 263 predictions of different signatures.

2643.1 Simulation, prediction and spatial smoothness of hydrological signatures introduction

Figure 1 illustrates predictions of three example hydrologic signatures (mean annual discharge, slope of the flow duration curve, and the baseflow index) from both random forests and the SAC model. Mean discharge can be predicted very well by a random forest based on catchment descriptors $\left(\mathrm{R}^{2}=0.92\right)$ and can be also simulated remarkably well by the conceptual hydrological model SAC calibrated by minimizing the RSME $\left(\mathrm{R}^{2}\right.$ $=0.98$ ). In contrast, the performance of both the random forest and SAC is poor when it comes to the slope of the flow duration curve $\left(\mathrm{R}^{2}=0.29\right.$ and $\mathrm{R}^{2}=0.15$, respectively). The baseflow index is predicted (by the random forest) and simulated (by SAC) better than the slope of the flow duration curve, but worse than the mean annual discharge $\left(\mathrm{R}^{2}=0.64\right.$ and $\mathrm{R}^{2}=0.84$, respectively). Note that for these three signatures, the performance of the random forest and of SAC are related: both methods perform well for the mean annual discharge, reasonably well for the baseflow index, and poorly for the slope of the flow duration curve.

Interestingly, the performance of both the random forest and SAC is related to the spatial smoothness of the hydrological signatures. Note how the mean discharge field varies smoothly across space, whereas the slope of the flow duration curve exhibits large changes over short distances (first row of Figure 1). To quantify the spatial smoothness, we used Moran's $I$ to measure the spatial auto-correlation (Appendix 2). $I$ enables us to quantify features that are clear visually, and to compare signatures based on the spatial smoothness of their field. The spatial smoothness is the highest for the mean discharge ( $I$ $=0.51)$, intermediate for the baseflow index $(I=0.16)$ and the lowest for the slope of the flow duration curve $(I=0.09)$. This ranking is the same as the ranking based on the performance of the random forest and SAC. In other words, Figure 1 suggests that signatures with lower spatial smoothness may be harder to relate to catchment characteristics and to simulate using a conceptual model.

\subsection{Simulation, prediction and spatial smoothness of hydrological signatures - evaluation for 15 signatures}

Figure 2 shows that there is a strong three-way relationship between how well signatures can be predicted based on catchment attributes, how well they can be simulated by SAC, and the smoothness of their spatial variability over the CONUS. The signatures in Figure 2 are ordered from left to right based on how well they can be predicted using a random forest. Like for Figure 1, we compared the observed and predicted signatures from the random forest by computing the coefficient of determination $\mathrm{R}^{2}$, shown in light blue in Figure 2. $\mathrm{R}^{2}$ varies from 0.92 (mean annual discharge) to 0.29 (slope of the flow duration curve). The performance of the random forest is compared to that of SAC, shown in dark blue in Figure 2. It is clear that hydrological signatures that can be accurately predicted from catchment attributes by the random forest can also be well simulated by SAC. Indeed, the performance of the random forest and that of SAC, each described by $15 \mathrm{R}^{2}$ 
values, are highly correlated $(\rho=0.91)$. Note that several signatures we considered were also predicted by Beck et al. (2015) using characteristics from thousands of catchments from across the world and neural networks. They also find that some signatures are better predicted than others and interestingly, it appears that if they had ranked signatures based on the $\mathrm{R}^{2}$ they report in their Figure 5, the ranking would have been very similar to what we propose (with the mean annual flow and half-flow date being best predicted, followed by the high-flow quantile, and finally the low flow quantile and the baseflow index).

Furthermore, the spatial smoothness measured by Moran's I (shown in green in Figure 2) is almost systematically greater for signatures that can be accurately predicted by the random forest and well simulated by SAC. In fact, the correlation between the performance of the random forest and spatial smoothness is strong $(\rho=0.91)$. This suggests that random forests fail to capture sudden (small-scale) changes in hydrological signatures over short distances. The spatial smoothness also appears to be a good predictor of how well hydrological signatures are captured by SAC $(\rho=0.78)$.

The remarkable similarity between the performance of the random forests and SAC is somewhat surprising given that the two methods are fundamentally different. The random forest is based on catchment attributes (not on hydrometeorological time series, although some catchment attributes are shaped by hydrometeorological conditions described by the time series) and is a statistical framework that is not constrained by physical processes. In contrast, SAC is a conceptual hydrological model conditioned by hypotheses on catchment behavior imbedded in its formulation, it requires daily time series (random forests only have access to climatic averages) and its parameters are determined by an automated discharge calibration procedure (they were not inferred from catchment attributes). Further, the random forests were trained to capture each hydrological signature independently, but SAC was only trained to optimize RMSE (note that this does not prevent SAC from providing better estimates of most signatures, as shown by Figure 2).

\section{$334 \quad 3.3$ Climatic indices as strongest predictors of hydrological signatures}

335 Recall from Figures 1 and 2 that hydrological signatures well predicted by random forests climatic indices have a smooth pattern over the CONUS, and when they are highly correlated to signatures, those signatures inherit their smooth pattern. This is clear in Figure 3: the spatial patterns of climate indices shown in the first row (originally selected by Berghuijs et al., 2014) are similar to the signatures in the second row. The maps of mean annual discharge and the runoff ratio show very similar patterns to that of the aridity map, while the half-flow date principally reflects the precipitation seasonality and the fraction of precipitation falling as snow. In contrast, the maps in the bottom row of poorly predicted signatures show a noisier spatial pattern and lack a clear relationship to the climatic indices shown in the first row.

To better understand why some signatures were better predicted than others, we explored which predictors were preferentially used by the random forest. To this end, we consider 
the IncMSE, the increase in the MSE of the prediction when the value for each predictor were shuffled. IncMSE is indicated by the size of the dots in Figure 4. The color of the dots indicates the Spearman rank correlation coefficient between each attribute and signature. Most of the influential predictors in the random forest are climatic variables. If we restrict attention to the 14 pairs of catchment attributes-hydrological signatures with IncMSE $>20 \%, 11$ of them involve a climatic variable (aridity alone accounts for 6 pairs). In this respect, the climatic indices exert a stronger influence on hydrological signatures than the topographic, soil, land cover and geological attributes combined.

The large influence of climatic conditions on hydrological behavior is not new. Aridity is commonly regarded as the main driver of water partitioning at the land surface (Budyko, 1974; Hrachowitz et al., 2013). The influence of climate on hydrological regimes is well acknowledged (Berghuijs et al., 2014), yet it is debated whether this influence is direct, via the water balance, or indirect, via the long-term influence of climate on the landscape (Harman and Troch, 2014). Importantly, climatic variables do not only drive current, but probably also trends induced by climate change (Rice et al., 2016). Overall, our results are consistent with those of Beck et al. (2015), who predicted a range of hydrological signatures using catchment attributes and reported that climate indices exerted the strongest influence, while predictors related to soils and geology were less important.

The importance of aridity is clear and its control over the water balance receives continuous attention, sustained by the high number of studies based on the Budyko framework (Padrón et al., 2017). Yet, Figure 4 shows that several hydrological variables, which reflect key aspects of hydrological dynamics, are poorly predicted by aridity alone, or even by a combination of climatic indices. For instance, random forests were unable to clearly relate climate indices to the precipitation-streamflow elasticity, the slope of the flow duration curve or the no-flow frequency. The variations in space of these signatures (bottom row of Figure 3) appear to be too complex to be captured by correlation coefficients, or by a more complex statistical model (random forest) or by a conceptual hydrological model (SAC). In other words, the number of hydrological signatures that can be well predicted based on climatic indices alone is limited.

\section{$380 \quad 3.4$ Weak influence of land cover, soil and geology on hydrological behavior?}

381 We found that climatic indices have by far the greatest influence on selected hydrological 382 signatures, while the attributes characterizing the land cover, soil, geology and 383 topography have a much weaker influence. The lack of dark colors in the corresponding 384 columns of Figure 4 indicate that those attributes, when considered individually, are not 385 strongly correlated to hydrological signatures. Even when those attributes are combined with other attributes using a random forest, their influence is generally insignificant, as shown by the lack of the large circles in the same columns. The relative strength of climatic variables when compared to other catchment attributes has the following implication. When a hydrological signature is strongly linked to one or several climate indices, it is well predicted, and conversely, weak links lead to poor predictions. Hence, climatic attributes strongly condition how well hydrological signatures can be predicted by the random forest. Some signatures like the slope of the flow duration curve are not 
well constrained by climate variables, and the random forest is not able to extract relevant information from the predictors we are using.

The lack of significance of land cover, soil and geology attributes shown in Figure 4 is consistent with the finding of Beck et al. (2015), as mentioned previously. Merz and Bloschl (2009) similarly showed that event runoff coefficients in 459 Austrian catchments were barely influenced by land cover, soil types, and geology, and were better explained by climate-related indices. In contrast, when exploring and classifying 116 near-natural catchments in the UK, Chiverton et al. (2015) found that geology, the depth to gleyed layer in soils and the percentage of arable land were good discriminants. Likewise, Singh et al. (2014) found geology and land use do matter when choosing donor catchments, but their influence depend on the region.

We find that land cover, soil and geology attributes are weak predictors, yet this does not mean that land cover, soil and geology do not influence hydrological processes. It rather tells us that their influence on hydrological signatures can be missed by standard catchment attributes, data sets and machine learning techniques, such as those used in this study, for the following reasons:

1. Spatial scale: the scale that which vegetation, soil, geological processes occur is often several orders of magnitude smaller than what our finest data sets or models can capture. Key properties are difficult to measure in the first place and also difficult to upscale in a way that preserves their influence on water dynamics. For instance, aggregate soil types likely do not represent the heterogeneity that governs matrix flow in watersheds and essential information is lost when computing catchment-scale averages. This stresses the importance of upscaling methods preserving landscape properties across scales (Samaniego et al., 2010; Rakovec et al., 2016).

2. Data quality and uncertainty: Data quality has been brought up to explain why soil and geological data are not good predictors of hydrological signatures (Beck et al., 2015). It is indeed likely that issues related to data collection (see discussion in Addor et al., 2017b) limit the predictive power of soil data. Further, note that landscape attributes considered here are all deterministic, but data sets like SoilGrids (Hengl et al., 2017) provide uncertainty estimates of soil characteristics, which may improve the predictions and make the influence of soils on water dynamics clearer.

3. Machine learning algorithm: Random forests may not have the agility to extract the full information available in the data sets we used as predictors. They fail in particular at capturing sudden changes in space, for instance the fields in Figure $1 \mathrm{j}$ are too smooth, but the basic equations constituting SAC lead to more spatial diversity (Figure 1k), although the accuracy is low in both cases.

4. Land cover, soil and geology are secondary predictors: they may play a significant role in differentiating catchment responses when climatic conditions are almost fixed. This assumption could be tested in future studies, by breaking down the sample of 671 catchments into sub-samples of catchments of similar climatic conditions and by repeating the analysis conducted here. 
Manuscript submitted to Water Resources Research on 17/01/2018.

These results stress that further work is needed to clarify the relationships between landscape attributes and hydrological signatures that are not well explained by climatic indices. Soil, geology and vegetation processes play an essential role in the water cycle, yet we find difficult it to capture their influence on discharge at the catchment scale, despite the diversity of hydro-climatic regimes and catchment attributes that we covered. We expect that predictions of hydrological signatures will be improved by better measurements and better upscaling techniques of catchment attributes, as well as by additional attributes, but that the improvements for climatedriven signatures will be more modest, since the predictions are already good.

\section{Discussion}

In the Results section we discussed how, as we move down the table of signatures shown in Figure 4, the quality of the predictions and simulations, the spatial smoothness of the signature fields and the influence of climate vary in consistent ways. We summarized these results in the top part of Table 3. In this Discussion section, we discuss the implications of these results for hydrologic research. We focus on challenges that emerge as we move down the table of signatures in three contexts: i) the sensitivity to discharge uncertainty and implications for signature regionalization, ii) the relation to hydrological processes and iii) the use of signatures for model calibration and evaluation.

\subsection{Sensitivity to discharge uncertainty and implications for signature regionalization}

In this study, we do not explicitly characterize errors in discharge time series resulting from rating curve uncertainties, nor how those uncertainties propagate into hydrological signatures. These aspects were however investigated by Westerberg et al. (2016) for 43 UK catchments. They found that the impacts of rating curve uncertainties on hydrological signatures depend on the catchment of interest and on the type of signature. Some signatures, such as the mean discharge, are far less sensitive to rating curve uncertainty than others, such as the slope of the flow duration curve (as illustrated by their Figure 6). Similarly, low flow signatures are more sensitive to data errors than high flow signatures. They also regionalized signatures following a weighted-pooling-group approach, in which each signature was estimated using the weighted mean of its value in similar catchments (similarity was defined based on mean annual precipitation, the $90^{\text {th }}$ percentile catchment elevation, the base-flow index and catchment area). Their regionalization performs better for high flows than for low flows, and better for the mean discharge than for the slope of the flow duration curve (their Figure 8). This is not only consistent with the sensitivity of the signatures to rating curve uncertainties that they determined, but also with the ranking of signatures we propose based on random forest regionalization.

Westerberg et al. (2016) underscored that uncertainty in discharge time series complicates and deteriorates the regionalization of hydrological signatures. Here we do not characterize discharge uncertainties. Instead, we approach the regionalization challenge from a different perspective. Using a greater number of catchments and Moran's $I$ as a measure of spatial correlation, we show that the signatures identified by Westerberg et al. (2016) as sensitive to rating curve uncertainty tend to vary abruptly 
over short distances (low Moran's I, toward the bottom of the signature table shown in Figure 4). Those signatures would be poorly regionalized when selecting the closest catchments as donors, since the value of the signature typically vary significantly among those catchments (for reasons that are currently unclear). In other words, the spatial interpolation of signatures is easier when their field varies in smooth (predictable) fashion. It is likely that the sudden variations over space for some signatures, which we argue make regionalization difficult, come in part from discharge uncertainties.

\subsection{Relation to hydrological processes - questionable discriminative power of hydrological signatures}

An essential question, when it comes to the variations of signatures in space, is whether differences between catchments for a given signature truly reflect differences in hydrological processes, or rather, data and method uncertainties.

Ideally, we would like signatures to provide insights into hydrological processes, in order to advance process understanding and modeling. But signatures are also influenced by how data are collected (Westerberg and McMillan, 2015; McMillan et al., 2017). For instance, the frequency of zero discharge is impacted by the fact that different stations report very low flows differently, which is likely to contribute to the strong variations in space (Figure 3i) and to partly explain why the random forest predictions and the SAC simulations are particularly poor for this signature (Figure 2). Further, the formulation of the signature influences its value, and if it is not robust enough, it can exacerbate insignificant differences or mask significant differences between catchments. For instance, streamflow-precipitation elasticity can be formulated in different ways, some being less sensitive to outliers (Sankarasubramanian et al., 2001). It is well possible that other signatures suffer from similar drawbacks: their aim is clear, but their formulation does not capture well that they should because it is lacking robustness.

Note that uncertainties related to data and methods are only two factors making it difficult to isolate and understand differences in behavior between catchments. A more general issue is that, while signatures enable us to explore hydrological behavior, they do not necessarily allow us to pinpoint the hydrological processes leading to this behavior. For instance, the slope of the flow duration can be related to myriad of processes which are difficult to disentangle and which interact in complex ways. Similarly, both baseflow generation and the snow melt contribute to the slowly-varying part of a hydrograph, but discharge separation techniques used to compute the baseflow index (such as digital filters) are unable to distinguish between these two processes. Also, both evapotranspiration and loss to groundwater lead to low values of the runoff ratio, but the runoff ratio on its own does not inform us on this partitioning. Furthermore, statistics based on high discharge thresholds enable us to explore the frequency and amplitude of floods, but do not account for the different processes leading to floods. In most cases, signatures do not enable us to focus on a single process, but rather, reflect the interplay of several processes. As a consequence of this diversity of processes, it is difficult to establish clear links between landscape attributes and hydrological signatures. 
There are few exceptions, for instance the seasonality of discharge is in many cases determined by the seasonality of precipitation and the eventual presence of snow, and the mean discharge is strongly controlled by the aridity (top of the signature table). But overall, the hydrological drivers of many signatures are still unclear. Hydrological signatures are promising tools, but the results showed here illustrate that research on hydrological signatures is still at an early stage, since we still do not understand many of them well enough to explain what is driving their changes in space. We think that this should make us re-evaluate what they tell us on hydrological processes. To give one example, the precipitation-discharge elasticity is commonly used for anticipate the future impact of climate change on discharge, yet even recent research recognizes that "it is difficult to identify physical reasons, for the spatial variations in elasticity values" (Andréassian et al., 2016). If we are not able to explain how elasticity changes in space, is it reasonable to rely on it to produce projections of discharge under future climate, that will potentially support decision-making on adaptation strategies? We recognize the value of assessing the sensitivity of discharge to precipitation, but we wonder whether sensitivity is correctly captured by this specific signature (and hence, how much faith we should put into it).

\subsection{Hydrological signatures for model calibration and selection}

SAC performs overall better than the random forests (Figure 2). It captures very well the mean annual, winter and summer discharge, the half-flow date and the baseflow index. Q95 is also well captured, which should not come as a surprise since RMSE was used as objective function. Yet, our results reveal that other signatures, such as the low flows metrics, the slope of the flow duration curve and the discharge-streamflow elasticity are poorly captured. This reflects that using a general metric such as RMSE can deliver a good overall performance, but does not provide enough constrains to capture specific parts of the hydrograph, which may contain important information on catchment behavior (De Boer-Euser et al., 2017).

To overcome this issue, an option is to use hydrological signatures in the parameter estimation process (e.g., Vrugt and Sadegh, 2013). It is not clear however, how these signatures should be selected. Based on the results presented in this study, we hypothesize that signatures from the bottom of the table shown in Figure 4 have relatively low value for model calibration if their uncertainties are not accounted for. These signatures can be strongly influenced by data and method uncertainties, so approaching them from a deterministic perspective and trying to exactly match them may not bring much, since it means using a hydrological model to mimic variations over space that are only partially related to hydrological processes. Again, in this study, we do not explicitly assess how data and formulation uncertainties propagate into the signatures. Yet, the wider range in the random forest predictions and the scatter in the maps of these signatures indicate that they are particularly uncertain. The signatures we identify as uncertain are also considered as uncertain by Westerberg et al. (2016). Future research should systematically assess the value of signatures. Model calibration using a wide range of signatures in a wide range of catchments would help us to better assess which 
572 Our concerns about model calibration using signatures impacted by data and methods 573 uncertainties also apply to model evaluation (and by extension, to model comparison). 574 Signatures at the bottom of the table are particularly uncertain and their relationship to catchment characteristics remain elusive (i.e., we do not have a good handle on those signatures). To use an example, we can predict the mean discharge in space well, which provides us with a reference models can be compared to. In contrast, if we consider the slope of the flow duration curve, it is poorly constrained by observations. Although we can compute its value, we cannot explain its variations in space, hence we question whether this reference is robust enough to enable model comparison. In absence of uncertainty estimates, we do not think that a model should be selected instead of another model, based solely on its better representation of signatures from the bottom of the table.

\section{Conclusions and outlook}

We systematically explored how landscape attributes influence (or not) hydrological signatures. We described the landscape of 671 catchments in the contiguous USA using five classes of attributes (topography, climatology, land cover, soil and geology) and summarized catchment behaviour using 15 hydrological signatures. Random forests allowed us to combine those landscape characteristics in non-linear ways and to quantitatively explore their relative influence on hydrological signatures. We found that climatic attributes are by far the most influential predictors for signatures that can be well-predicted based on catchment attributes (such as the mean annual discharge or the half-flow date), with land cover, soil and geology attributes playing secondary roles. Yet, several other signatures, such as the slope of the flow duration curve or the streamflowprecipitation elasticity are poorly predicted based on catchments attributes, and in particular, could not be satisfactorily predicted by climatic indices alone.

Using a large sample of catchments enabled us to explore the spatial patterns of hydrological signatures over the CONUS, and to characterize their spatial smoothness (auto-correlation) using Moran's $I$. We found that spatial smoothness is a simple yet powerful way to gain insights into a variety of aspects of large-sample studies. Signatures with smooth spatial variations are typically those with a high spatial predictability. In contrast, when signatures exhibit abrupt changes over short distances, those changes usually cannot be related to catchment attributes using random forests and they are also poorly captured by hydrological simulations from a conceptual model. Those sudden variations make signature regionalization difficult if neighbouring catchments are used as donors. The reasons behind noisy spatial patterns are not entirely clear and deserve more attention.

In summary, we found strong relationships between i) our ability to capture hydrological signatures using simulations from a conceptual hydrological model (SAC), ii) our ability to predict them using catchment characteristics as predictors in a machine-learning algorithm (random forests), iii) the spatial smoothness of the maps of these signatures (characterized using Moran's $I$ ) and iv) the strength of the climate influence on those 616 hydrological signatures (Figure 4). Signatures at the bottom of this ranking are poorly 
related to catchment attributes, poorly captured by SAC, their spatial pattern is noisy, and 618 based on results from other studies, they are also particularly susceptible to discharge 619 uncertainties and difficult to regionalize. In other words, these signatures are poorly constrained by discharge observations and the drivers of their variations in space are elusive. Hence in absence of uncertainty estimates for these signatures, we question their reliability to formulate conclusions on hydrological processes and we do not recommend them for the evaluation and selection of hydrological models. Those findings are outlined in Table 3.

Future research could explore whether signatures at the top of the ranking deliver better results when used for the calibration and selection of hydrological models. Another research avenue would be to re-use the framework presented here and explore how our conclusions vary when a subsample of catchments is selected in order to explore a specific landscape feature. We hope that the ideas and results presented in this study will trigger discussions on the drivers of hydrological processes at the catchment scale and on the use of hydrological signatures for hydrological modeling.

\section{Appendix 1: An introduction to regression trees and random forests}

We chose to use a machine-learning tool (random forests, Breiman, 2001) to explore how the interplay between landscape attributes shapes hydrological behavior. Machinelearning algorithms are gaining in popularity as the quantity and diversity of data to process increase. Machine-learning algorithms have been shown to be powerful prediction techniques, including in hydrologic studies (e.g., Gudmundsson and Seneviratne, 2013; Beck et al., 2015). Here we present a brief introduction to random forests, which may be useful for the interpretation of our results.

A random forest relies on an ensemble of regression trees to relate predictors (here catchment attributes) to a response variable (here a hydrological signature). In a regression tree, the prediction is made based on a series of threshold-based conditions on the predictors. The prediction scheme is initiated at the top of the tree (in the example shown in Figure A1a, the question at the top split is whether the mean elevation is greater than $1151 \mathrm{~m}$ ). The prediction is then refined using other thresholds on other (and sometimes the same) predictors at lower levels of the tree. The influence of each predictor on the response variable can be estimated based on its position in the regression tree: predictors appearing higher in the tree have a higher separating/predictive power (Figure A1a indicates that mean elevation is a strong predictor of the base flow index, likely because it conditions the formation a snow pack, which will increase the baseflow index when it melts). Note that regression trees are typically not symmetrical (different variables are used in different parts of the tree).

Regression trees are grown following a "recursive binary splitting" approach. The procedure starts at the top of the tree and at each split, one variable and one threshold are selected in order to minimize the mean squared error (MSE) of the prediction. The prediction is the mean value of the predictor for all the elements (catchments) falling in each class. As a consequence, the predictions of a decision tree are discrete values (one 
per terminal node, such as 0.4801 for the left-most terminal node of the tree shown in

663 Figure A1a, which leads to the horizontally aligned back points in Figure A1b). Trees are

664 grown and then pruned by minimizing the cross-validated MSE in order to reduce the risk of overfitting. While regression trees are intuitive to interpret and can deal with nonlinear relationships between variables, they typically lack robustness. We found that regression trees produced by randomly excluding half of the catchments to be quite different in the predictive variables they selected and in the position of these variables in the tree.

To overcome this limitation, we used random forests instead of single regression trees. Random forests are an ensemble of regression trees (here we used 500 trees per forest). The robustness of the forest comes from the way each tree is grown. At each split, a subsample of predictors is randomly excluded and the prediction must be done using solely the remaining. This implies that strong predictors, which otherwise might have been used for this specific split, will be excluded. This introduces differences between the trees, making the prediction more robust than if all the trees were similar. The number of trees $N$ and the number of predictors $P$ excluded at each split are variables defined by the user. We found that variations around the default value for $P$ (a third of the total number of predictors) has little influence on our predictions, and that $N=500$ is adequate because it leads to better predictions than small forests, but more trees did not improve the predictions.

Since it is not practical to inspect each tree to determine which variables are used for the prediction, the relative influence of the predictors of a random forest is measured in an automated way. Once the forest has been grown, each predictor is considered individually and its values are shuffled (their statistical distribution remains the same but their order is now random). The relative drop in prediction accuracy (expressed in \%) indicates how influential this predictor is (large increases in MSE indicate influential predictors). Figure A1c shows that for the prediction of the baseflow by a random forest, the fraction of precipitation falling as snow is the most influential predictor.

An advantage of growing a random forest is that the ensemble of trees can be used to characterize the uncertainty in the prediction. We used QQ plots to assess the reliability of the ensembles and found that for all the hydrological signatures except the fraction of no flow, the ensembles are remarkably reliable (Figure A1d). Although this is not a feature we use in this study, we consider important to stress this finding, as it can be relevant in other contexts, for instance for parameter estimation based on regionalized hydrological signatures. Finally, note that because the deterministic prediction of each random forest is the mean prediction of its regression trees, the predictions are continuous values. This reduces the granularity of the predictions when compared to regression trees, which only predict a limited number of discrete values (Figure A1b).

\section{Appendix 2: Moran's I as a measure of spatial smoothness}

704 
When a variable is plotted on a map for numerous catchments, spatial patterns can appear and help with the formulation of starting hydrological hypotheses. A fundamental advantage of large-sample hydrology over small-sample hydrology is that, when maps are produced using hundreds of catchments, those insights are likely to be clearer than if the maps were based on a handful of catchments, because those tend to be patchier.

In this study, we explore and quantify regional variability in hydrological signatures using a measure of spatial smoothness. Addor et al. (2017b) observed that maps of climate indices generally exhibit smoother patterns than maps of hydrological signatures, whose patterns tend to be noisier (with potentially strong differences between adjacent catchments). Similar differences in spatial variability can also be observed among hydrological signatures: some signatures vary gradually across the landscape, while others exhibit abrupt changes over short distances. This is already apparent in earlier studies. Figure 2 of Sawicz et al. (2011) indicates for instance that the runoff ratio over the Eastern United States varies more smoothly in space than the slope of the flow duration curve.

To quantify the smoothness of spatial patterns in maps of hydrological signatures, we measure the spatial autocorrelation using Moran's I (Moran, 1950; Legendre and Legendre, 1998):

where $x$ is the variable of interest with $N$ elements (here $N=671$ catchments), $\bar{x}$ is its mean, $w$ is the weight associated with each pair of catchments (here $w=1 / d$, where $d$ is the distance along a great circle between the two catchments, the diagonal elements of the matrix $w$ being set to 0 ) and $\mathrm{W}$ is the sum of all the weights. Spatial correlation can be related to temporal autocorrelation: if all the pairs of data points close in space (in time) have a similar value, then the field is spatially (temporally) auto-correlated. Differences (or similarities) between points far apart have a comparatively small influence on $I$ because of the distance-based weighting system selected. $I$ values close to 0 indicate no spatial correlation. The higher the value $I$, the greater the spatial auto-correlation and the smother the spatial patterns (compare Figures 2a, e and i for an example). Note that in contrast to correlation coefficients, $|I|$ can exceed 1 (de Jong et al., 1984).

\section{Acknowledgements}

This work was supported by the US Army Corps of Engineers Climate Preparedness and Resilience programs. The National Center for Atmospheric Research (NCAR) is sponsored by the US National Science Foundation. Funding from the Swiss National Science Foundation is acknowledged (grant P2ZHP2_161963). We thank Pablo Mendoza for recommending QQplots for the evaluation of the random forest. The CAMELS hydrometeorological time series (https://doi.org/10.5065/D6MW2F4D) and attributes 
Manuscript submitted to Water Resources Research on 17/01/2018.

747

748

749

750

751

752

753

754

755

756

757

758

759

760

761

762

763

764

765

766

767

768

769

770

771

772

773

774

775

776

777

778

779

780

781

782

783

784

785

786

787

788

789

790

791

(https://doi.org/10.5065/D6G73C3Q, version 2.1 is used in this study) are freely available online.

\section{References}

Addor, N., Newman, A. J., Mizukami, N. and Clark, M. P.: Catchment attributes for large-sample studies, , doi:10.5065/D6G73C3Q, 2017a.

Addor, N., Newman, A. J., Mizukami, N. and Clark, M. P.: The CAMELS data set: catchment attributes and meteorology for large-sample studies, Hydrol. Earth Syst. Sci., 21(10), 5293-5313, doi:10.5194/hess-21-5293-2017, $2017 \mathrm{~b}$.

Almeida, S. L., Bulygina, N., Mcintyre, N., Wagener, T. and Buytaert, W.: Predicting flows in ungauged catchments using correlated information sources, Proc. Br. Hydrol. Soc. Elev. Natl. Symp. Hydrol. a Chang. world, Dundee, July 2012, 1-7, doi:10.7558/bhs.2012.ns02, 2012.

Almeida, S., Le Vine, N., McIntyre, N., Wagener, T. and Buytaert, W.: Accounting for dependencies in regionalized signatures for predictions in ungauged catchments, Hydrol. Earth Syst. Sci., 20(2), 887-901, doi:10.5194/hess-20-887-2016, 2016.

Anderson, E. A.: National Weather Service River Forecast System - Snow accumulation and ablation model, Tech. Memo. NWS HYDRO-17., 1973.

Andréassian, V., Coron, L., Lerat, J. and Le Moine, N.: Climate elasticity of streamflow revisited - An elasticity index based on long-term hydrometeorological records, Hydrol. Earth Syst. Sci., 20(11), 4503-4524, doi:10.5194/hess-20-4503-2016, 2016.

Beck, H. E., de Roo, A. and van Dijk, A. I. J. M.: Global maps of streamflow characteristics based on observations from several thousand catchments, J. Hydrometeorol., 150423121816007, doi:10.1175/JHM-D-14-0155.1, 2015.

Berghuijs, W. R., Sivapalan, M., Woods, R. A. and Savenije, H. H. G.: Patterns of similarity of seasonal water balances: A window into streamflow variability over a range of time scales, Water Resour. Res., 50, 5638-5661, doi:10.1002/2014WR015692, 2014.

De Boer-Euser, T., Bouaziz, L., De Niel, J., Brauer, C., Dewals, B., Drogue, G., Fenicia, F., Grelier, B., Nossent, J., Pereira, F., Savenije, H., Thirel, G. and Willems, P.: Looking beyond general metrics for model comparison - Lessons from an international model intercomparison study, Hydrol. Earth Syst. Sci., 21, 423-440, doi:10.5194/hess-21-4232017, 2017.

Breiman, L.: Random forests, Mach. Learn., 45(1), 5-32, doi:10.1023/A:1010933404324, 2001.

Budyko, M. I.: Climate and life, New York Academic Press., 1974.

Burnash, R. J. C., Ferral, R. L. and McGuire, R. A.: A generalized streamflow simulation system: Conceptual modeling for digital computers., 1973.

Chaney, N. W., Wood, E. F., McBratney, A. B., Hempel, J. W., Nauman, T. W., Brungard, C. W. and Odgers, N. P.: POLARIS: A 30-meter probabilistic soil series map of the contiguous United States, Geoderma, 274, 54-67, doi:10.1016/j.geoderma.2016.03.025, 2016.

Chiverton, A., Hannaford, J., Holman, I., Corstanje, R., Prudhomme, C., Bloomfield, J. and Hess, T. M.: Which catchment characteristics control the temporal dependence structure of daily river flows?, Hydrol. Process., 29(6), 1353-1369, doi:10.1002/hyp.10252, 2015. 

Hydrological field data from a modeller's perspective: Part 2: Process-based evaluation of model hypotheses, Hydrol. Process., 25(4), 523-543, doi:10.1002/hyp.7902, 2011. Clausen, B. and Biggs, B. J. F.: Flow variables for ecological studies in temperate streams: Groupings based on covariance, J. Hydrol., 237(3-4), 184-197, doi:10.1016/S0022-1694(00)00306-1, 2000. of the Relationships of Soil Moisture Characteristics to the Physical Properties of Soils, Water Resour. Res., 20(6), 682-690, doi:10.1029/WR020i006p00682, 1984. Court, A.: Measures of streamflow timing, J. Geophys. Res., 67(11), 4335-4339, doi:10.1029/JZ067i011p04335, 1962. Crawford, N. H. and Linsley, R. K.: Digital simulation in hydrology: Stanford Watershed Model IV., 1966.

806 conceptual rainfall-runoff models, Water Resour. Res., 28(4), 1015-1031, 807 doi:10.1029/91WR02985, 1992.

808 Euser, T., Winsemius, H. C., Hrachowitz, M., Fenicia, F., Uhlenbrook, S. and Savenije, 809 H. H. G.: A framework to assess the realism of model structures using hydrological 810 signatures, Hydrol. Earth Syst. Sci., 17(5), 1893-1912, doi:10.5194/hess-17-1893-2013, 8112013.

812 Falcone, J. A.: GAGES-II: Geospatial Attributes of Gages for Evaluating Streamflow. 813 [online] Available from: 814 https://water.usgs.gov/GIS/metadata/usgswrd/XML/gagesII_Sept2011.xml, 2011.

815 Gleeson, T., Moosdorf, N., Hartmann, J. and van Beek, L. P. H.: A glimpse beneath 816 earth's surface: GLobal HYdrogeology MaPS (GLHYMPS) of permeability and porosity, 817 Geophys. Res. Lett., 41, 3891-3898, doi:10.1002/2014GL059856, 2014.

818 Gudmundsson, L. and Seneviratne, S. I.: Do land parameters matter in large-scale 819 terrestrial water dynamics? - Toward new paradigms in modelling strategies, Hydrol. 820 Earth Syst. Sci. Discuss., 10(11), 13191-13229, doi:10.5194/hessd-10-13191-2013, 2013. 821 Gupta, H. V., Wagener, T. and Liu1, Y.: Reconciling theory with observations: elements 822 of a diagnostic approach to model evaluation, Hydrol. Process., 22, 3802-3813, 823 doi:10.1002/hyp.6989, 2008.

824 Harman, C. and Troch, P. A.: What makes Darwinian hydrology "darwinian"? Asking a 825 different kind of question about landscapes, Hydrol. Earth Syst. Sci., 18(2), 417-433, 826 doi:10.5194/hess-18-417-2014, 2014.

827 Hartmann, J. and Moosdorf, N.: The new global lithological map database GLiM: A 828 representation of rock properties at the Earth surface, Geochemistry, Geophys. 829 Geosystems, 13(12), 1-37, doi:10.1029/2012GC004370, 2012.

830 Hengl, T., Mendes De Jesus, J., Heuvelink, G. B. M., Gonzalez, M. R., Kilibarda, M., 831 Blagotí, A., Shangguan, W., Wright, M. N., Geng, X., Bauer-Marschallinger, B., 832 Guevara, M. A., Vargas, R., MacMillan, R. A., Batjes, N. H., Leenaars, J. G. B., Ribeiro, 833 E., Wheeler, I., Mantel, S. and Kempen, B.: SoilGrids250m: Global Gridded Soil 834 Information Based on Machine Learning, PLoS One, 12(2), e0169748, 835 doi:10.1371/journal.pone.0169748, 2017.

836 Hrachowitz, M., Fovet, O., Ruiz, L., Euser, T., Gharari, S., Nijzink, R., Freer, J., 837 Savenije, H. H. G. and Gascuel-Odoux, C.: Process consistency in models: The 
838 importance of system signatures, expert knowledge, and process complexity, , 7206839 7230, doi:10.1002/2013WR014956.Received, 2014.

840 Hrachowitz, M., Savenije, H. H. G., Blöschl, G., McDonnell, J. J., Sivapalan, M., 841 Pomeroy, J. W., Arheimer, B., Blume, T., Clark, M. P., Ehret, U., Fenicia, F., Freer, J. E., 842 Gelfan, A., Gupta, H. V., Hughes, D. a., Hut, R. W., Montanari, A., Pande, S., Tetzlaff, 843 D., Troch, P. a., Uhlenbrook, S., Wagener, T., Winsemius, H. C., Woods, R. a., Zehe, E. 844 and Cudennec, C.: A decade of Predictions in Ungauged Basins (PUB) - a review, 845 Hydrol. Sci. J., 58(6), 1198-1255, doi:10.1080/02626667.2013.803183, 2013.

846 James, G., Witten, D., Hastie, T. and Tibshirani, R.: An Introduction to Statistical 847 Learning with Applications in R, edited by Springer., 2013.

848 de Jong, P., Sprenger, C. and van Veen, F.: On Extreme Values of Moran's I and Geary's 849 c, Geogr. Anal., 16(1), 17-24, doi:10.1111/j.1538-4632.1984.tb00797.x, 1984.

850 Kuentz, A., Arheimer, B., Hundecha, Y. and Wagener, T.: Understanding hydrologic 851 variability across Europe through catchment classification, Hydrol. Earth Syst. Sci., 21, 852 2863-2879, doi:10.5194/hess-21-2863-2017, 2017.

853 Ladson, A., Brown, R., Neal, B. and Nathan, R.: A standard approach to baseflow 854 separation using the Lyne and Hollick filter, Aust. J. Water Resour., 17(1), 25-34, 855 doi:http://dx.doi.org/10.7158/W12-028.2013.17.1., 2013.

856 Laio, F. and Tamea, S.: Verification tools for probabilistic forecasts of continuous 857 hydrological variables, Hydrol. Earth Syst. Sci., 11(4), 1267-1277, doi:10.5194/hess-11858 1267-2007, 2007.

859 Lawrence, D. M. and Slater, A. G.: Incorporating organic soil into a global climate model, Clim. Dyn., 30(2-3), 145-160, doi:10.1007/s00382-007-0278-1, 2008.

862 Liaw, A. and Wiener, M.: Classification and Regression by randomForest, R News, 2(3), 863 18-22, 2002.

864 McMillan, H. K., Clark, M. P., Bowden, W. B., Duncan, M. and Woods, R. A.: 865 Hydrological field data from a modeller's perspective: Part 1. Diagnostic tests for model 866 structure, Hydrol. Process., 25(4), 511-522, doi:10.1002/hyp.7841, 2011.

867 McMillan, H., Westerberg, I. and Branger, F.: Five guidelines for selecting hydrological 868 signatures, Hydrol. Process., 1-5, doi:10.1002/hyp.11300, 2017.

869 Miller, D. A. and White, R. A.: A Conterminous United States Multilayer Soil 870 Characteristics Dataset for Regional Climate and Hydrology Modeling, Earth Interact., 871 2(2), doi:10.1175/1087-3562(1998)002<0002:CUSMS>2.0.CO;2, 1998.

872 Moran, P. A. P.: Notes on Continuous Stochastic Phenomena, Biometrika, 37(1/2), 17, 873 doi:10.2307/2332142, 1950.

874 Newman, A. J., Clark, M. P., Sampson, K., Wood, A., Hay, L. E., Bock, A., Viger, R., 875 Blodgett, D., Brekke, L., Arnold, J. R., Hopson, T. and Duan, Q.: Development of a 876 large-sample watershed-scale hydrometeorological dataset for the contiguous USA: 877 dataset characteristics and assessment of regional variability in hydrologic model 878 performance, Hydrol. Earth Syst. Sci., 19, 209-223, doi:10.5194/hess-19-209-2015, 8792015.

880 Newman, A. J., Sampson, K., Clark, M. P., Bock, A., Viger, R. J. and Blodgett, D.: A 881 large sample watershed-scale hydrometeorological dataset for the contiguous USA, , 882 doi:10.5065/D6MW2F4D, 2014.

883 Olden, J. D. and Poff, N. L.: Redundancy and the choice of hydrologic indices for 
Manuscript submitted to Water Resources Research on 17/01/2018.

884 characterizing streamflow regimes, River Res. Appl., 19(2), 101-121, 885 doi:10.1002/rra.700, 2003.

886 Padrón, R. S., Gudmundsson, L., Greve, P. and Seneviratne, S. I.: Large-Scale Controls 887 of the Surface Water Balance Over Land: Insights From a Systematic Review and Meta888 Analysis, Water Resour. Res., 1-20, doi:10.1002/2017WR021215, 2017.

889 Pelletier, J. D., Patrick D. Broxton, Hazenberg, P., Zeng, X., Troch, P. A., Niu, G.-Y., 890 Williams, Z., Brunke, M. A. and Gochis, D.: A gridded global data set of soil, intact 891 regolith, and sedimentary deposit thicknesses for regional and global land surface 892 modeling, J. Adv. Model. Earth Syst., 8, doi:10.1002/2015MS000526, 2016.

893 Priestley, C. H. B. and Taylor, R. J.: On the Assessment of Surface Heat Flux and 894 Evaporation Using Large-Scale Parameters, Mon. Weather Rev., 100(February), 81-92, 895 doi:10.1175/1520-0493(1972)100<0081:OTAOSH>2.3.CO;2, 1972.

896 R Core Team: R: A Language and Environment for Statistical Computing, [online] 897 Available from: http://www.r-project.org/, 2017.

898 Rakovec, O., Kumar, R., Mai, J., Cuntz, M., Thober, S., Zink, M., Attinger, S., Schäfer, 899 D., Schrön, M. and Samaniego, L.: Multiscale and Multivariate Evaluation of Water 900 Fluxes and States over European River Basins, J. Hydrometeorol., 17(1), 287-307, doi:10.1175/JHM-D-15-0054.1, 2016.

Renard, B., Kavetski, D., Kuczera, G., Thyer, M. and Franks, S. W.: Understanding predictive uncertainty in hydrologic modeling: The challenge of identifying input and structural errors, Water Resour. Res., 46(5), 1-22, doi:10.1029/2009WR008328, 2010.

Rice, J. S., Emanuel, R. E. and Vose, J. M.: The influence of watershed characteristics on spatial patterns of trends in annual scale streamflow variability in the continental U.S., J. Hydrol., 540, 850-860, doi:10.1016/j.jhydrol.2016.07.006, 2016.

Samaniego, L., Kumar, R. and Attinger, S.: Multiscale parameter regionalization of a grid-based hydrologic model at the mesoscale, Water Resour. Res., 46(5), doi:10.1029/2008WR007327, 2010.

Sankarasubramanian, A., Vogel, R. M. and Limbrunner, J. F.: Climate elasticity of streamflow in the United States, Water Resour. Res., 37(6), 1771-1781, doi:10.1029/2000WR900330, 2001.

Sawicz, K., Wagener, T., Sivapalan, M., Troch, P. a. and Carrillo, G.: Catchment classification: Empirical analysis of hydrologic similarity based on catchment function in the eastern USA, Hydrol. Earth Syst. Sci., 15(9), 2895-2911, doi:10.5194/hess-15-28952011, 2011.

Singh, R., Archfield, S. A. and Wagener, T.: Identifying dominant controls on hydrologic parameter transfer from gauged to ungauged catchments - A comparative hydrology approach, J. Hydrol., 517, 985-996, doi:10.1016/j.jhydrol.2014.06.030, 2014.

Snelder, T. H., Lamouroux, N., Leathwick, J. R., Pella, H., Sauquet, E. and Shankar, U.: Predictive mapping of the natural flow regimes of France, J. Hydrol., 373(1-2), 57-67, doi:10.1016/j.jhydrol.2009.04.011, 2009.

Thornton, P. E., Thornton, M. M., Mayer, B. W., Wilhelmi, N., Wei, Y. and Cook, R. B.: Daymet: Daily surface weather on a 1km grid for North America, 1980-2012., 2012.

Troch, P. A., Martinez, G. F., Pauwels, V. R. N., Durcik, M., Sivapalan, M., Harman, C., Brooks, P. D., Gupta, H. and Huxman, T.: Climate and vegetation water use efficiency at catchment scales, Hydrol. Process., 23, 2409-2414, doi:10.1002/hyp.7358, 2009.

929 Viger, R. J. and Bock, A.: GIS Features of the Geospatial Fabric for National Hydrologic 
930 Modeling., 2014.

931 Vrugt, J. A. and Sadegh, M.: Toward diagnostic model calibration and evaluation: 932 Approximate Bayesian computation, Water Resour. Res., 49(7), 4335-4345, 933 doi:10.1002/wrcr.20354, 2013.

934 Westerberg, I. K. and McMillan, H. K.: Uncertainty in hydrological signatures, Hydrol. 935 Earth Syst. Sci., 19(9), 3951-3968, doi:10.5194/hess-19-3951-2015, 2015.

936 Westerberg, I. K., Wagener, T., Coxon, G., McMillan, H. K., Castellarin, A., Montanari, 937 A. and Freer, J.: Uncertainty in hydrological signatures for gauged and ungauged 938 catchments, Water Resour. Res., 52, 1847-1865, doi:10.1002/2015WR017635, 2016.

939 Woods, R. A.: Analytical model of seasonal climate impacts on snow hydrology: 940 Continuous snowpacks, Adv. Water Resour., 32, 1465-1481, 941 doi:10.1016/j.advwatres.2009.06.011, 2009.

942 Yilmaz, K. K., Gupta, H. V. and Wagener, T.: A process-based diagnostic approach to 943 model evaluation: Application to the NWS distributed hydrologic model, Water Resour.

944 Res., 44(May), 1-18, doi:10.1029/2007WR006716, 2008.

945 Zeng, X.: Global Vegetation Root Distribution for Land Modeling, J. Hydrometeorol., 946 2(5), 525-530, doi:10.1175/1525-7541(2001)002<0525:GVRDFL>2.0.CO;2, 2001. 


\section{Table 1: Catchment attributes}

\begin{tabular}{|c|c|c|c|}
\hline \multicolumn{4}{|c|}{ camels_topo - Topography and location } \\
\hline Description & Unit & Data source & References \\
\hline gauge latitude & ${ }^{\circ}$ north & N15 - USGS data & \\
\hline gauge longitude & ${ }^{\circ}$ east & N15 - USGS data & \\
\hline catchment mean elevation & $\begin{array}{l}\text { meter above } \\
\text { sea level }\end{array}$ & N15 - USGS data & \\
\hline catchment mean slope & $\mathrm{m} / \mathrm{km}$ & N15 - USGS data & \\
\hline catchment area (GAGESII estimate) & $\mathrm{km}^{2}$ & N15 - USGS data & Falcone (2011) \\
\hline catchment area (Geospatial Fabric estimate) & $\mathrm{km}^{2}$ & $\begin{array}{l}\text { N15 - Geospatial } \\
\text { Fabric }\end{array}$ & $\begin{array}{l}\text { Viger (2014), Viger and Bock } \\
\text { (2014) }\end{array}$ \\
\hline
\end{tabular}

camels_clim - Climate indices - *: Computed over the period 1989/10/01 to 2009/09/30

\section{Description}

mean daily precipitation

Unit

$\mathrm{mm} /$ day

Data source

mean daily PET [estimated by N15 using Priestley-Taylor

formulation calibrated for each catchment]

$m m / d a y$

aridity (PET/P, ratio of mean PET [estimated by N15 using

Priestley-Taylor formulation calibrated for each catchment] to

mean precipitation)

seasonality and timing of precipitation (estimated using sine curves to represent the annual temperature and preciptiation cycles, positive [negative] values indicate that precipitation peaks in summer [winter], values close to 0 indicate uniform precipitation throughout the year)

fraction of precipitation falling as snow (i.e., on days colder than $\left.0^{\circ} \mathrm{C}\right)$

frequency of high precipitation days ( $>=5$ times mean daily precipitation)

average duration of high precipitation events (number of consecutive days $>=5$ times mean daily precipitation)

season during which most high precipitation days ( $>=5$ times mean daily precip.) occur

frequency of dry days ( $<1 \mathrm{~mm} /$ day)

average duration of dry periods (number of consecutive days $<1$ $\mathrm{mm} /$ day)

season during which most dry days ( $<1 \mathrm{~mm} /$ day) occur

camels_vege - Land cover characteristics -

\section{Description}

forest fraction

maximum monthly mean of the leaf area index (based on 12

monthly means)

difference between the maximum and mimumum monthly

mean of the leaf area index (based on 12 monthly means)

maximum monthly mean of the green vegetation fraction

(based on 12 monthly means)

difference between the maximum and mimumum monthly

mean of the green vegetation fraction (based on 12 monthly

means)

dominant land cover type (Noah-modified 20-category IGBPMODIS land cover)

fraction of the catchment area associated with the dominant land cover

root depth (percentiles XX $=50$ and $99 \%$ extracted from a root days/year N15-Daymet*

days $\quad$ N15 - Daymet*

season N15 - Daymet*

days/year N15 - Daymet*

days N15 - Daymet*

season N15 - Daymet* depth distribution based on IGBP land cover)

\section{References}

N15 - Daymet*

N15 - Daymet*

N15 - Daymet*

N15 - Daymet*

Eq. 14 in Woods et al. (2009)

\begin{tabular}{|c|c|c|}
\hline Unit & Data source & References \\
\hline- & N15 - USGS data & \\
\hline - & MODIS* & \\
\hline- & MODIS* & \\
\hline - & MODIS* & \\
\hline - & MODIS* & \\
\hline- & MODIS* & \\
\hline - & MODIS* & \\
\hline $\mathrm{m}$ & MODIS* & Eq. 2 and Table 2 in Zeng (2001) \\
\hline
\end{tabular}


Table 1 continued: Catchment attributes

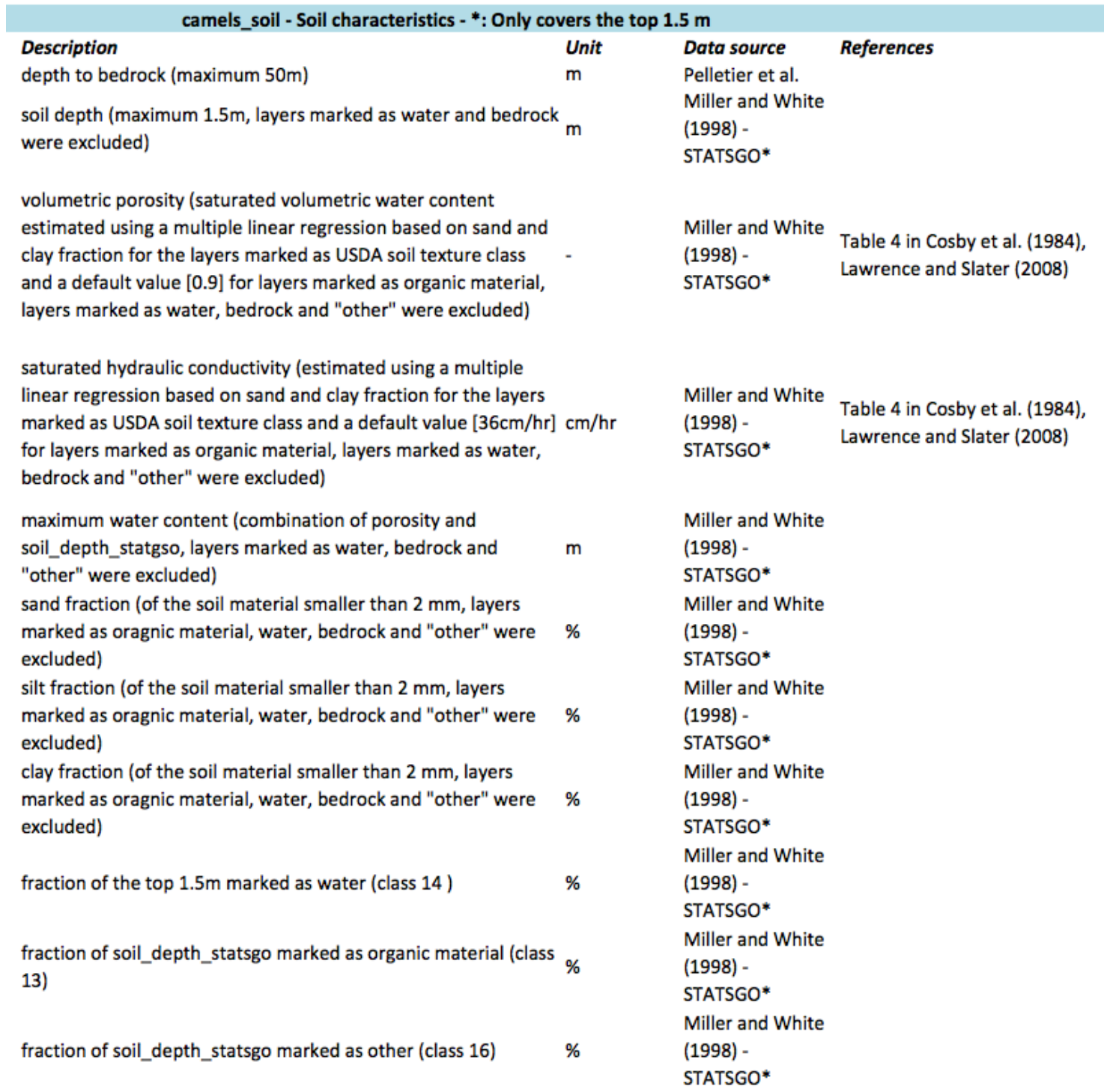

camels_geol - Geological characteristics

Description

most common geologic class in the catchment

fraction of the catchment area associated with its most

common geologic class

2nd most common geologic class in the catchment

fraction of the catchment area associated with its 2 nd most

common geologic class

fraction of the catchment area characterized as "Carbonate

sedimentary rocks"

subsurface porosity

subsurface permeability $(\log 10)$
Unit

$-$

-

- GLIM

- $\quad$ GLIM

- $\quad$ GLIM

- GLIM

- $\quad$ GLHYMPS

$\mathrm{m}^{2}$

\section{References}

Hartmann and Moosdorf (2012)

Hartmann and Moosdorf (2012)

Hartmann and Moosdorf (2012)

Hartmann and Moosdorf (2012)

Hartmann and Moosdorf (2012)

Gleeson et al. (2014)

Gleeson et al. (2014) 
Table 2: Hydrological signatures

961

\begin{tabular}{|c|c|c|c|}
\hline \multicolumn{4}{|c|}{ camels_hydro - Hydrological signatures - *: Period $1989 / 10 / 01$ to $2009 / 09 / 30$} \\
\hline Description & Unit & Data source & References \\
\hline mean annual discharge & $\mathrm{mm} /$ day & N15 - USGS data* & \\
\hline mean winter (DJF) discharge & $\mathrm{mm} /$ day & N15 - USGS data* & \\
\hline mean summer (JJA) discharge & $\mathrm{mm} /$ day & N15 - USGS data* & \\
\hline $\begin{array}{l}\text { runoff ratio (ratio of mean daily discharge to mean daily } \\
\text { precipitation) }\end{array}$ & - & N15 - USGS data* & Eq. 2 in Sawicz et al. (2011) \\
\hline $\begin{array}{l}\text { streamflow-precipitation elasticity (sensitivity of streamflow to } \\
\text { changes in precipitation at the annual time scale) }\end{array}$ & ra & N15 - USGS data* & $\begin{array}{l}\text { Eq. } 7 \text { in Sankarasubramanian et } \\
\text { al. (2001), the last element } \\
\text { being } P / Q \text { not } Q / P\end{array}$ \\
\hline $\begin{array}{l}\text { slope of the flow duration curve (between the log-transformed } \\
33 \text { rd and } 66 \text { th streamflow percentiles) } \\
\text { baseflow index (ratio of mean daily baseflow to mean daily }\end{array}$ & & N15 - USGS data* & Eq. 3 in Sawicz et al. (2011) \\
\hline $\begin{array}{l}\text { discharge, hydrograph separation performed using Ladson et } \\
\text { al. [2013] digital filter) }\end{array}$ & - & N15 - USGS data* & Ladson et al. (2013) \\
\hline $\begin{array}{l}\text { mean half flow date (date on which the cumulative discharge } \\
\text { since October 1st reaches half of the annual discharge) }\end{array}$ & day of year & N15 - USGS data* & Court (1962) \\
\hline $5 \%$ flow quantile (low flow) & $\mathrm{mm} /$ day & N15 - USGS data* & \\
\hline $95 \%$ flow quantile (high flow) & $\mathrm{mm} /$ day & N15 - USGS data* & \\
\hline frequency of high-flow days ( $>9$ times the median daily flow) & days/year & N15 - USGS data* & $\begin{array}{l}\text { Clausen and Biggs (2000), Table } \\
2 \text { in Westerberg and McMillan } \\
\text { (2015) }\end{array}$ \\
\hline $\begin{array}{l}\text { mean duration of high-flow events (number of consecutive } \\
\text { days }>9 \text { times the median daily flow) }\end{array}$ & days & N15 - USGS data* & $\begin{array}{l}\text { Clausen and Biggs (2000), Table } \\
2 \text { in Westerberg and McMillan } \\
\text { (2015) } \\
\text { Olden and Poff (2003), Table } 2\end{array}$ \\
\hline frequency of low-flow days ( $<0.2$ times the mean daily flow) & days/year & N15 - USGS data* & $\begin{array}{l}\text { in Westerberg and McMillan } \\
\text { (2015) }\end{array}$ \\
\hline $\begin{array}{l}\text { mean duration of low-flow events (number of consecutive } \\
\text { days }<0.2 \text { times the mean daily flow) }\end{array}$ & days & N15 - USGS data* & $\begin{array}{l}\text { Olden and Poff (2003), Table } 2 \\
\text { in Westerberg and McMillan } \\
\text { (2015) }\end{array}$ \\
\hline frequency of days with $Q=0 \mathrm{~mm} /$ day & $\%$ & N15 - USGS data* & \\
\hline
\end{tabular}


964 Table 3: Summary of the typical differences between signatures from the top and 965 bottom of the signature table shown in Figure 4

\section{Feature}

Results

Prediction by SAC

Prediction by random forest

Spatial field

Well constrained by climatic indices

Well constrained by soil, land cover and geological

attributes

Potential improvement of the prediction by better data

\section{Discussion}

Regionalization

Sensitivity to discharge

uncertainty and signature

formulation

Discriminative power

Recommend for model

evaluation

$\begin{aligned} & \text { Top of the } \\ & \text { Bable }\end{aligned}$
table

Good

Good

Smooth

Yes

No

Weak

Easy

Low

High

Yes
Poor

Poor

Noisy

No

No

Strong

Difficult

High

Questionable

Not without

uncertainty

quantification
Discussed in paper section

3.1 and 3.2

3.1 and 3.2

3.1 and 3.2

3.3

3.4

4.1

4.1

4.3

966

967 


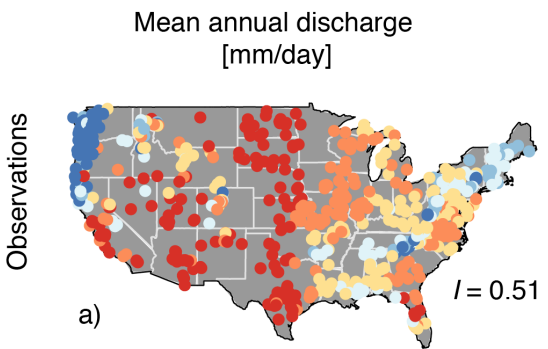

Baseflow index [-]
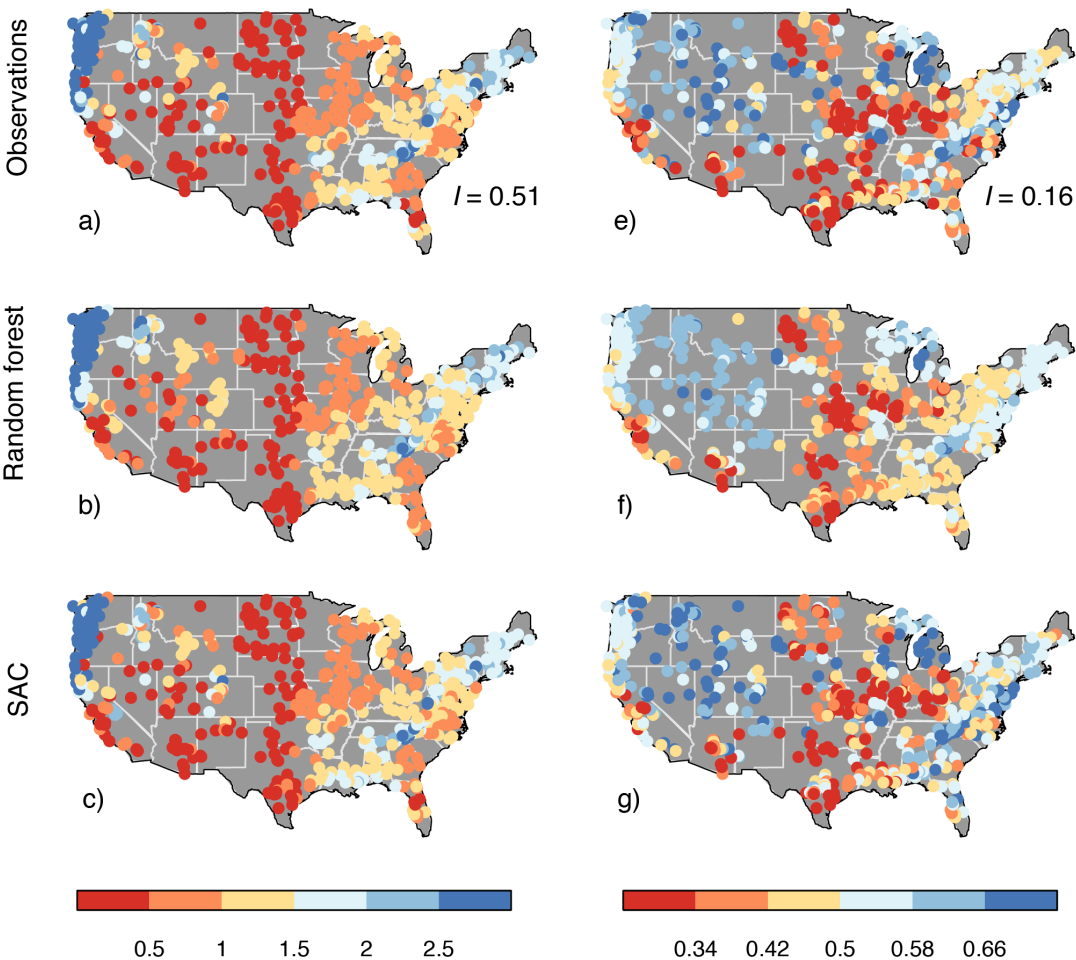

d)
$\frac{0}{d}$
$\frac{0}{\frac{\pi}{5}}$
$\frac{E}{5}$
$\frac{0}{0}$
$\frac{\Phi}{0}$
$\frac{0}{0}$
$\frac{d}{2}$

970

971

972 Figure 1: Comparison of the observed, predicted and simulated (first, second and third row, 973 respectively) mean annual discharge, baseflow index and slope of the flow duration curve (first, 974 second and third column, respectively). The spatial auto-correlation quantified using Moran's $I$ is 975 indicated for the maps of top row. The last row combines and compares the data from the three 976 977 978 maps of the same column and indicates the coefficient of determination $\mathrm{R}^{2}$ for the random forest predictions and SAC simulations computed over all the catchments.
Slope of the flow duration curve [-]
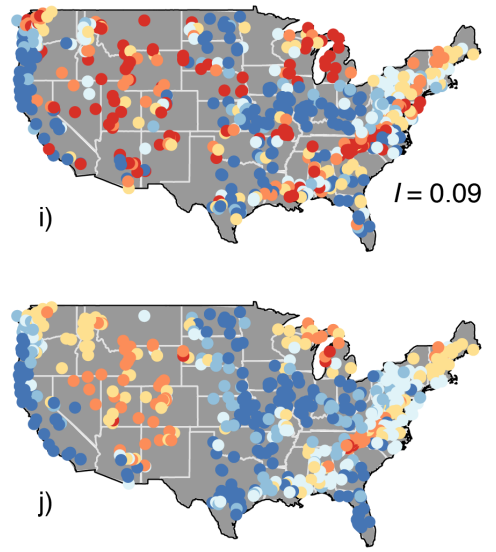

k)

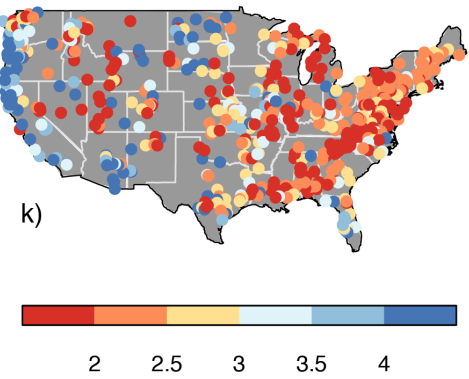

l)

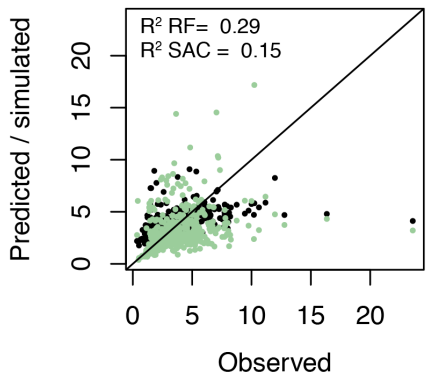




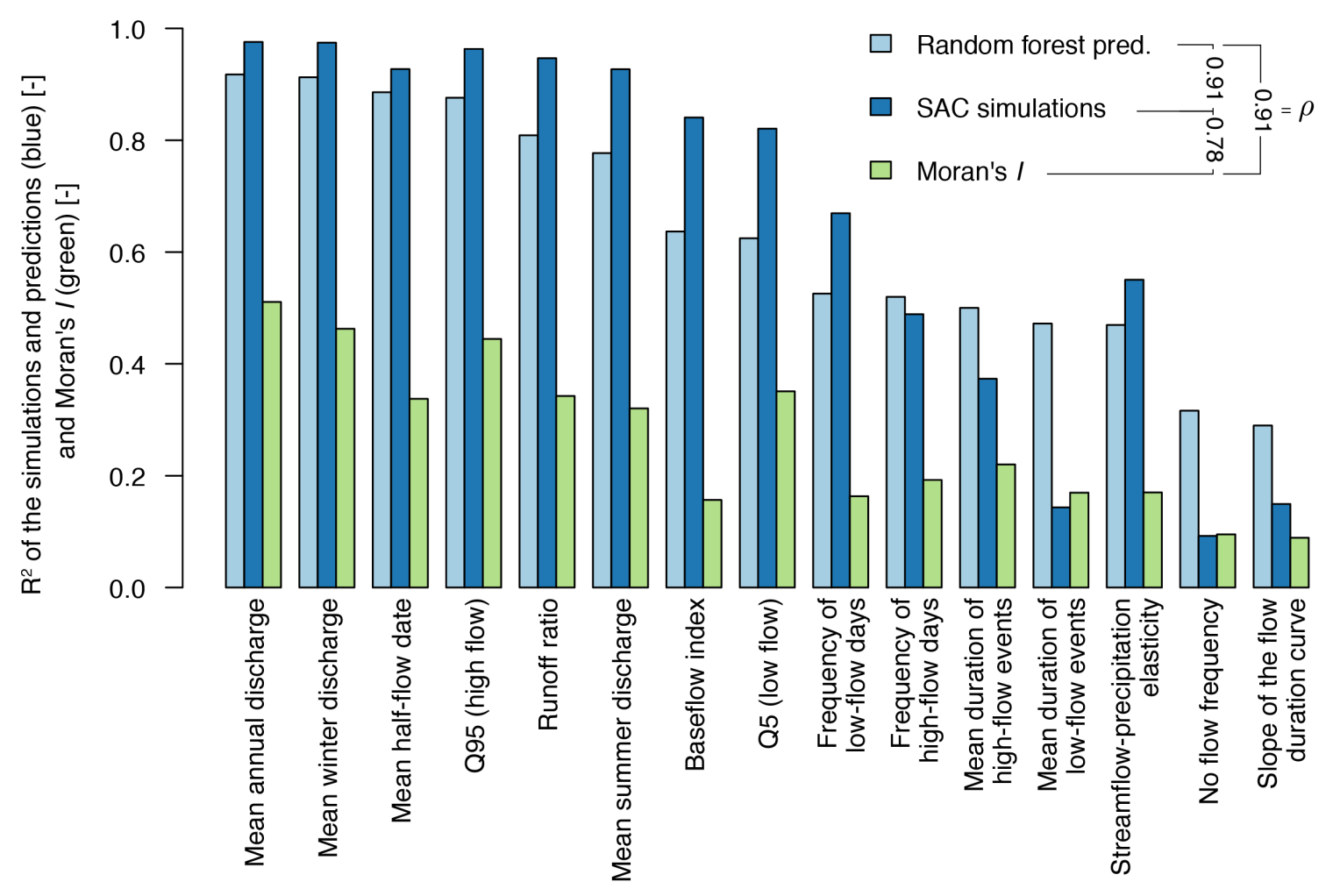

980 Figure 2: Illustration of the strong three-way relationship between how well signatures can be predicted based on catchment attributes using a random forest $\left(\mathrm{R}^{2}\right.$ between the observed and predicted signatures, light blue), how well they can be simulated by $\mathrm{SAC}$ ( $\mathrm{R}^{2}$ between the observed and simulated signatures, dark blue), and the smoothness of their spatial variability over the CONUS (Moran's I, green). The correlations between those variables are indicated in the predicted using a random forest. Each bar is based on at least 600 catchments. 

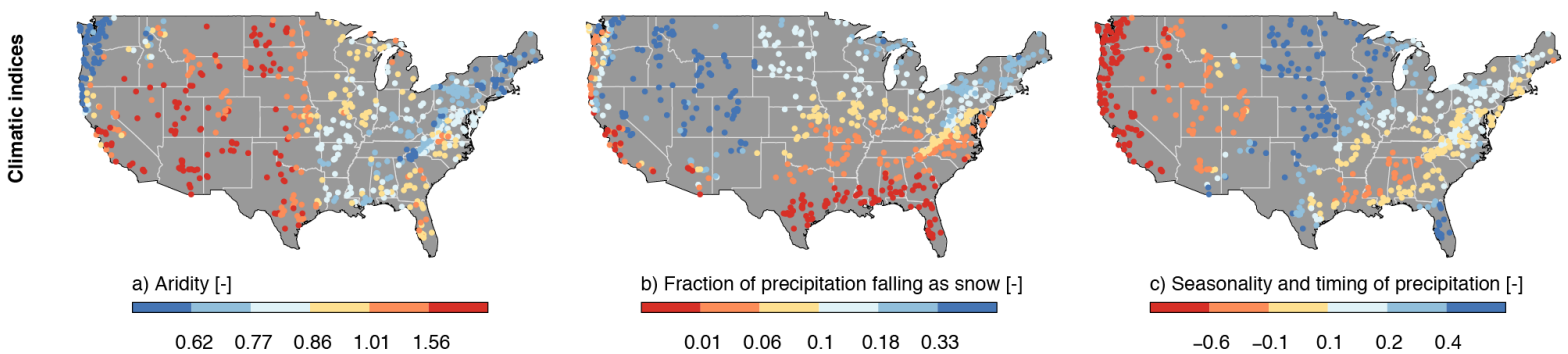

b) Fraction of precipitation falling as snow [-]

$\begin{array}{lllll}0.01 & 0.06 & 0.1 & 0.18 & 0.33\end{array}$

c) Seasonality and timing of precipitation [-]

$\begin{array}{lllll}-0.6 & -0.1 & 0.1 & 0.2 & 0.4\end{array}$
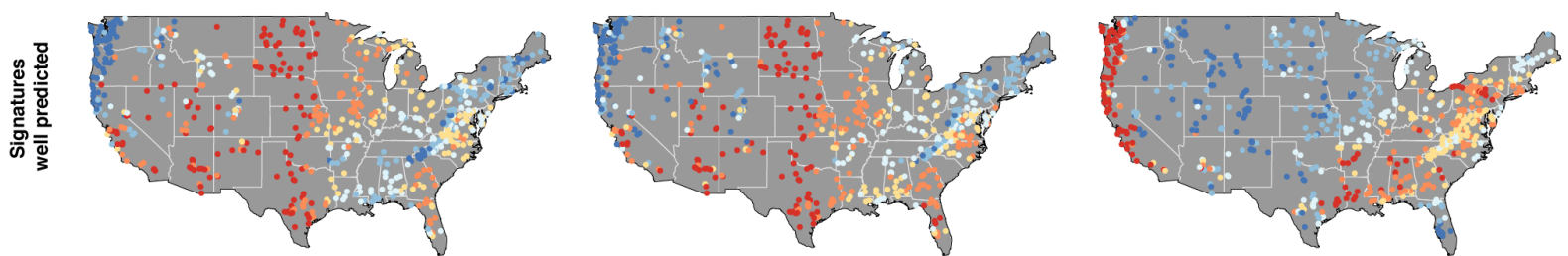

d) Mean annual discharge [mm/day]
$\begin{array}{llllll}0.35 & 0.83 & 1.13 & 1.5 & 2.08\end{array}$

e) Runoff ratio [-]

f) Mean half flow date [day of the year]

$\begin{array}{lllll}0.16 & 0.29 & 0.35 & 0.45 & 0.6\end{array}$
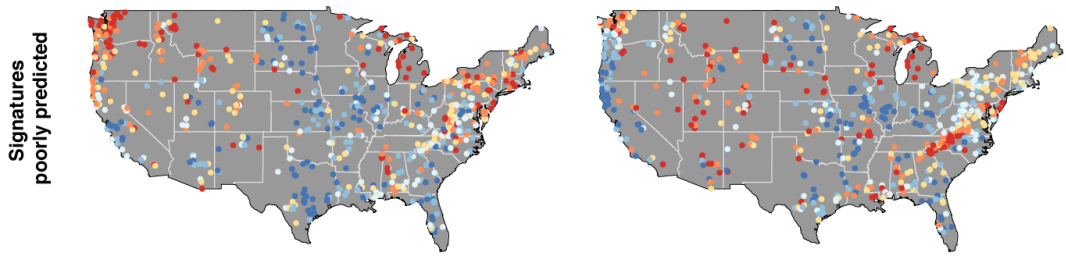

h) Slope of the flow duration curve [-]

g) Precipitation-streamflow sensitivity [-]

$\begin{array}{lllll}1.17 & 1.45 & 1.7 & 2.03 & 2.55\end{array}$

$\begin{array}{lllll}1.88 & 2.49 & 3.12 & 3.74 & 5.04\end{array}$

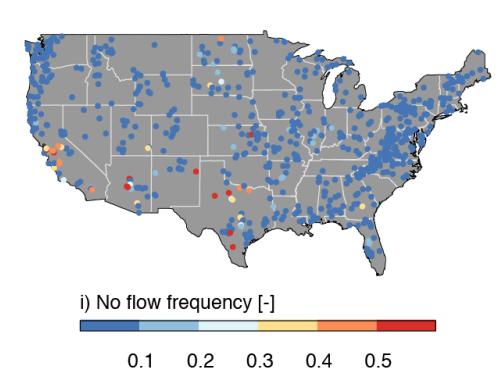

990 Figure 3: Comparison of the spatial patterns in climatic indices (top row), well-predicted

991 hydrological signatures (middle row) and poorly-predicated hydrological signatures (bottom

992 row). We used the same color scheme for all the maps to underscore similarities between them.

993 Note that units and break values vary. The break values were chosen so that each color class

994 encompasses about one sixth of the total number of catchments (except for the no flow

995 frequency).

996

997

998

999 


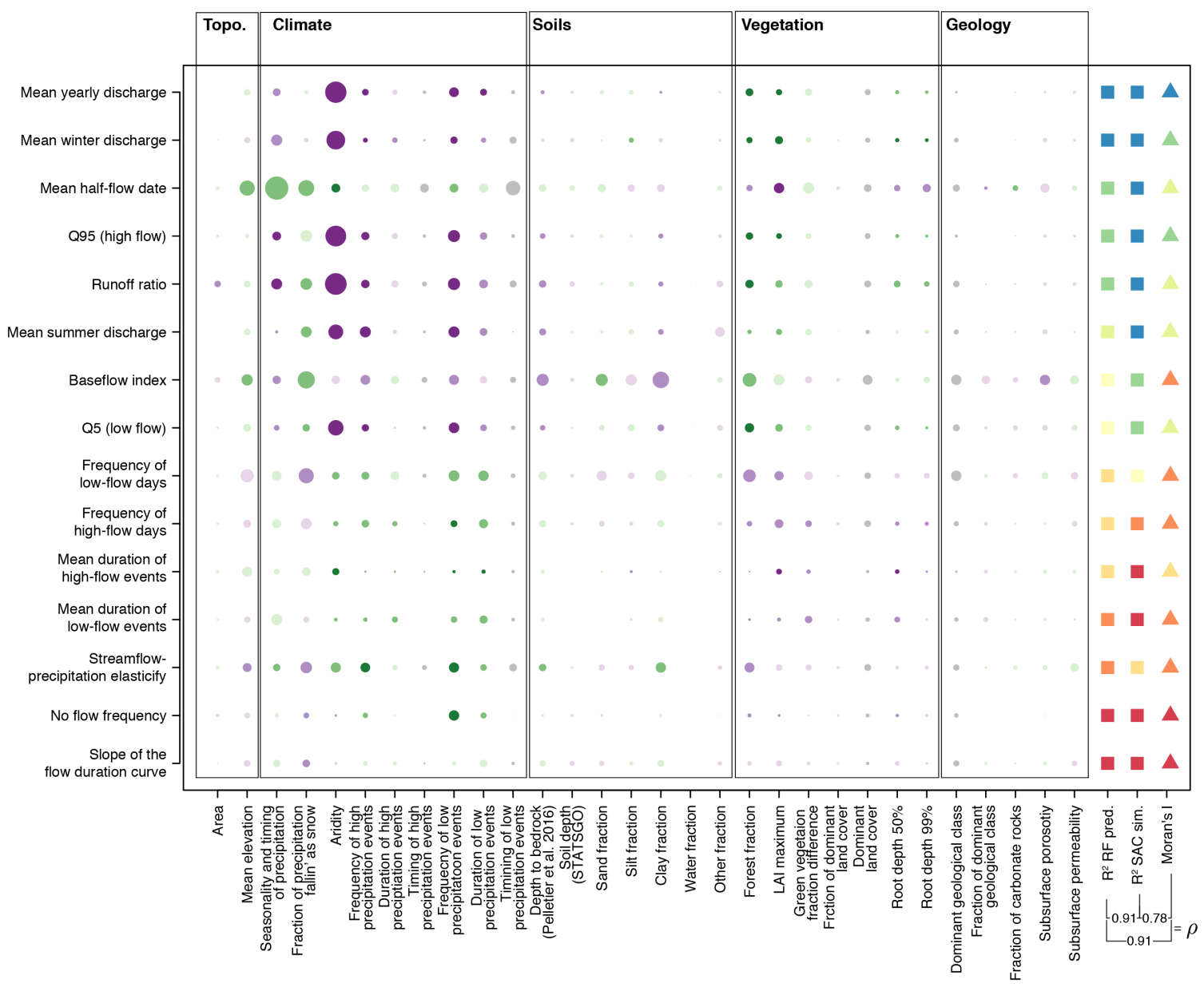

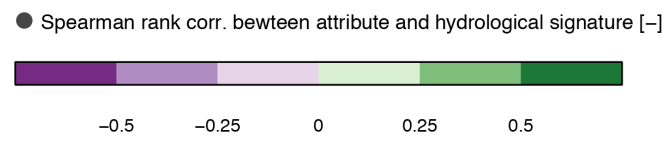

Influence of predictor in random forest: increase in mean squared error [\%]

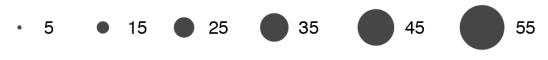

- Model fit: $\mathrm{R}^{2}$ observed vs. predicted/simulated hydrological signature [-]

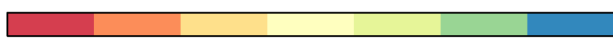

$\begin{array}{llllll}0.4 & 0.5 & 0.6 & 0.7 & 0.8 & 0.9\end{array}$

A Spatial smoothness: Moran's I [-]

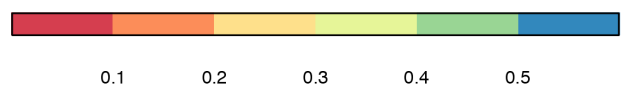

1000

1001

1002

1003

1004

1005

1006

1007

1008

1009

1010
Figure 4: Signature table synthesizing the main findings of this study. Catchment attributes (xaxis) are used to predict hydrological signatures (y-axis) using random forests. The signatures are ordered vertically based on how well they are captured by random forests. The influence of each catchment attribute on each signature in the random forest is measured by IncMSE and is proportional to the size of the dots. The three right-most columns summarize the data shown in Figure 2. 
a)

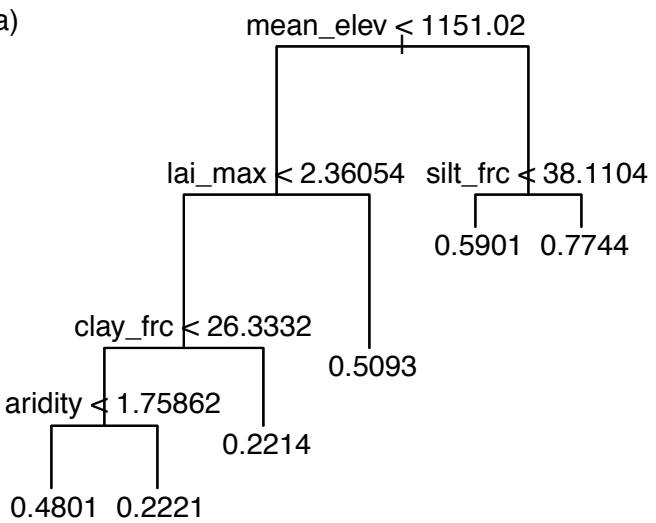

c)

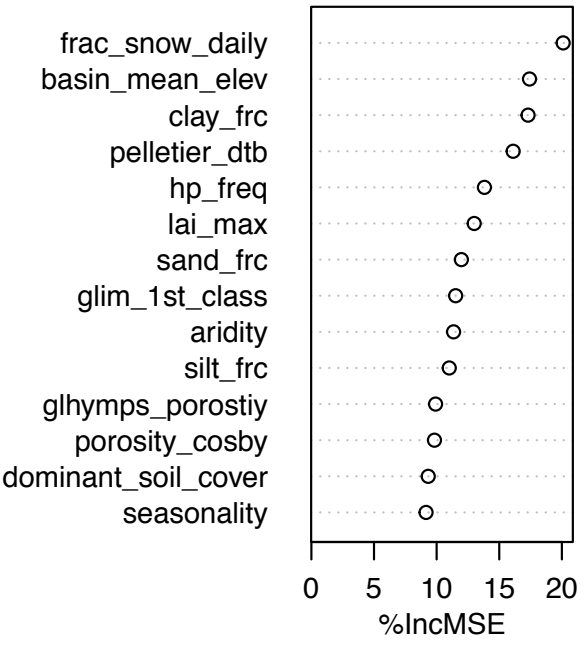

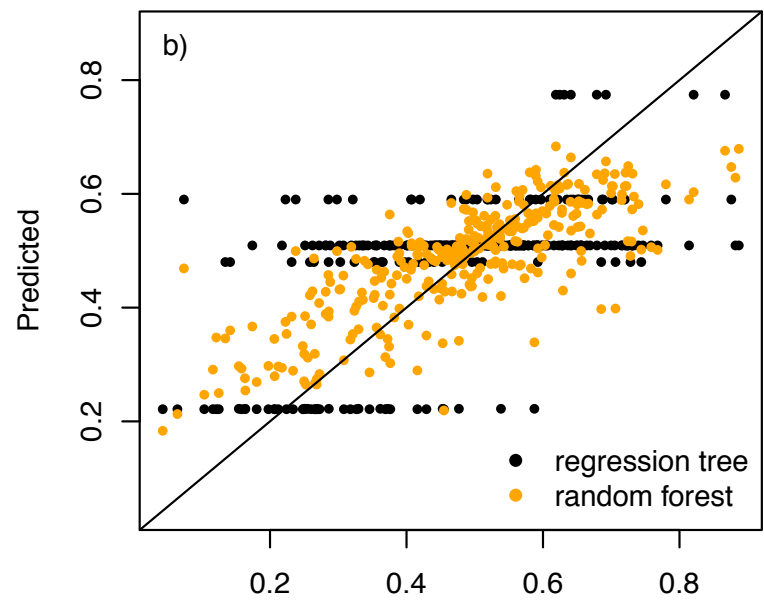

Observed

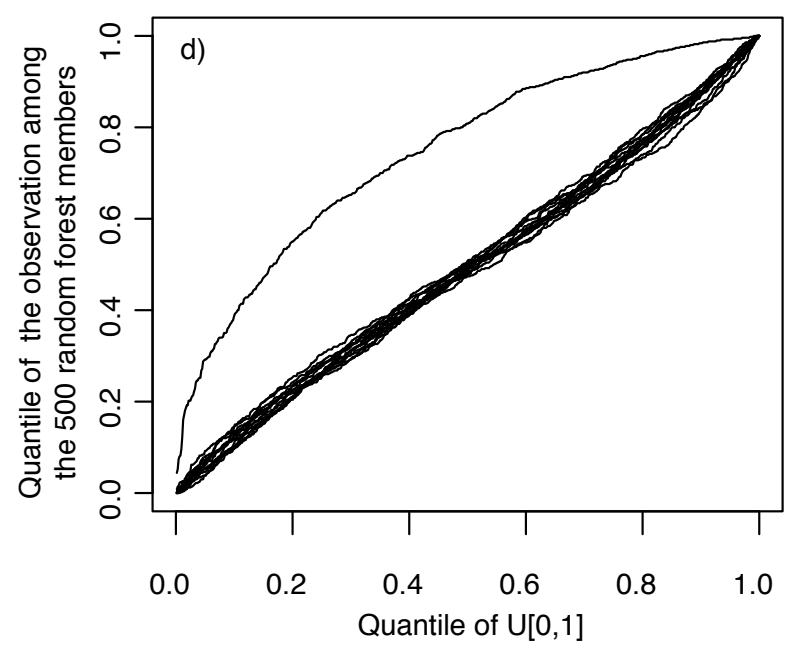

Figure A1: a) Example of a pruned regression tree trained to predict the baseflow index. b) Comparison of baseflow index observations to predictions from the regression tree shown in a) and from a random forest, whose most influential predictors are shown in c). c) Assessment of the relative influence of the random forest variables for the prediction of the baseflow index, the predictors are ordered from the most to least influential (top to bottom). d) QQplot for the 15 hydrological variables, lines close to the diagonal indicate reliable ensembles, the only line significantly departing from the diagonal is the fraction of no flow, see Laio and Tamea (2007) or Renard et al. (2010) for more details on how to interpret this plot. 